\begin{tabular}{|c|c|}
\hline \multirow{3}{*}{ 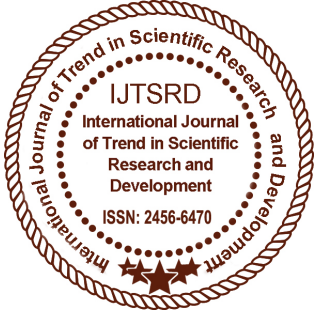 } & $\begin{array}{l}\text { International Journal of Trend in Scientific } \\
\text { Research and Development (IJTSRD) }\end{array}$ \\
\hline & International Open Access Journal \\
\hline & ISSN No: 2456 - 6470 | www.ijtsrd.com | Volume - 2 | Issue - 5 \\
\hline
\end{tabular}

\title{
A Universal Printed Antenna for UHF RFID Applications
}

\author{
Thein Kyithar \\ Lecturer, Department of Electronic Engineering, Pyay Technological University, \\ Republic of the Union of Myanmar, Pyay (Western Bago), Myanmar
}

\begin{abstract}
In this paper, a printed rectangular monopole antenna is designed for RFID (Radio Frequency Identification) reader applications. The antenna is designed to operate at a frequency of $860 \mathrm{MHz}$ to $960 \mathrm{MHz}$ allocated for UHF RFID universal (worldwide) band. The antenna simulation is analyzed using 3D EM simulator, FEKO Software. The result of the antenna parameters such as radiation pattern, reflection coefficient and gain are also discussed. The proposed antenna is simple in design and fair in size.
\end{abstract}

Keyword: printed rectangular monopole antenna, RFID, UHF, radiation pattern, return loss

\section{INTRODUCTION}

Radio Frequency Identification (RFID) is a form of wireless communication that uses radio waves to identify or track objects. These transmissions are of unique serial numbers or codes. This is known as a contactless technology whereby the tag or item does not need to be manually touched or wired. Now RFID finds many applications in various areas such as electronic toll collection, asset identification, retail item management, access control, animal tracking and vehicle security.

The common frequency used by RFID are low frequency $(125-134 \mathrm{kHz})$, high frequency $(13.56$ $\mathrm{MHz})$, ultra high frequency $(860-960 \mathrm{MHz})$, and microwave frequency(2.4-5.8 GHz).Radio waves behave differently at each of these frequencies with advantages and disadvantage associated with using each frequency band. RFID system consists of radio frequency transponders (tags), radio frequency transceivers (reader), and a host computer. The antennas for RFID systems also play a crucial role in the continuous development of this technology; it is the most important components in the optimization of the signal data to spread out into the air.

Printed monopole antenna is one of the most suitable antennas for achieving large bandwidth and omnidirectional radiation pattern. Printed monopole antennas are new version of micro strip antennas in which the ground plane below the patch is etched out. It gives wider bandwidth. Several printed monopole antenna configurations have been proposed and such antennas have been designed for various applications using different simulation software.

In this paper, a single band rectangular shaped printed monopole antenna for RFID reader application is designed to resonate on Ultra High Frequency (UHF) universal band of $860-960 \mathrm{MHz}$. The theoretical simulations are performed using FEKO Software.

\section{ANTENNA DESIGN}

The proposed design of printed rectangular monopole antenna is simple in construction. The antenna is designed for universal UHF (860-960 MHz) RFID applications. The antenna uses a $1.6 \mathrm{~mm}$ thick FR4 substrate with a relative permittivity of 4.4 and loss tangent of 0.02 .The front view of the antenna is shown in Figure 1 and the back view of the design is shown in Figure 2.

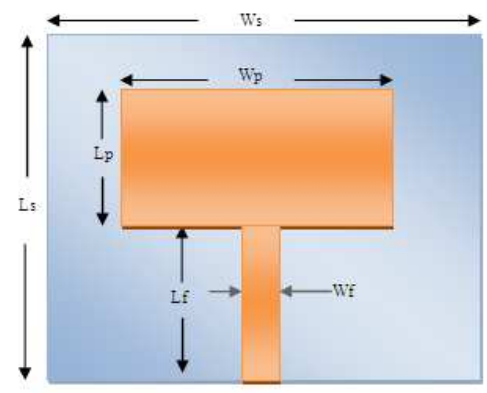

Figure1. Front View of the Antenna 


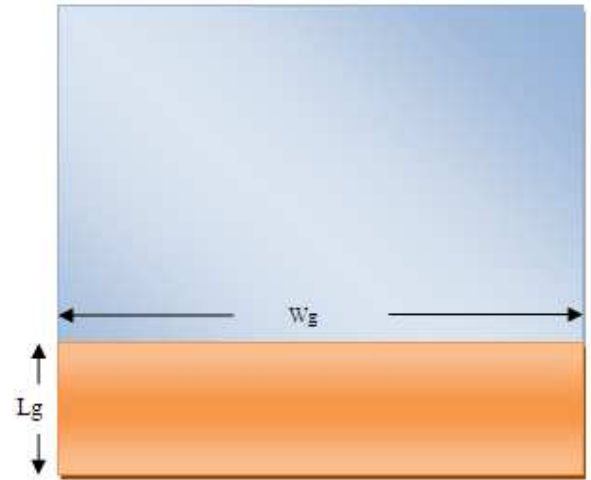

Figure2. Back View of the Antenna

The design of printed rectangular monopole antenna consists of substrate width (Ws), substrate length (Ls), antenna width $(\mathrm{Wp})$, antenna length ( $\mathrm{Lp}$ ) and a feed line which have impedance of $50 \mathrm{ohm}$ where its feed width (Wf) and feed length (Lf) are introduced. Dielectric substrate materials are used for design printed rectangular monopole antenna.

There are equations used to calculate Ws, Ls, Wp, Lp, Lf and Wf of the proposed antenna. The calculations are given as follows by equations (1) - (7).

Patch width,

$$
\mathrm{W}=\frac{c}{2 f 0}\left[\frac{\varepsilon r+1}{2}\right]^{-1 / 2}
$$

Where;

$\mathrm{f}_{\mathrm{o}}=$ operating frequency

? $\mathrm{r}=$ dielectric constant

$\mathrm{c}=$ speed of light

Effective dielectric constant,

$$
\varepsilon_{\text {reff }}=\frac{\varepsilon r+1}{2}+\frac{\varepsilon r-1}{2}\left[1+12 \frac{\mathrm{h}}{\mathrm{w}}\right]^{-1 / 2}
$$

Effective length,

$$
\mathrm{L}_{\mathrm{eff}}=\frac{c}{2 f 0[\text { sreff }]^{1 / 2}}
$$

Length extension,

$$
\Delta \mathrm{L}=0.412 \mathrm{~h} \frac{(\text { rreff }+0.3)(\mathrm{W} / \mathrm{h}+0.264)}{(\text { हreff }+0.258)(\mathrm{W} / \mathrm{h}+0.8)}
$$

Where;

$$
\mathrm{h}=\text { substrate thickness }
$$

Actual patch length,

$$
\mathrm{L}=\mathrm{L}_{\mathrm{eff}}-2 \Delta \mathrm{L}
$$

Ground plane extension $\mathrm{Lg} \neq \mathrm{Wg}$

$$
\begin{aligned}
& \mathrm{Lg}=6 \mathrm{~h}+\mathrm{L} \\
& \mathrm{Wg}=6 \mathrm{~h}+\mathrm{W}
\end{aligned}
$$

Where;

$$
\mathrm{h}=\text { substrate thickness }
$$

The feed line for the printed rectangular monopole antenna determines to be fed for $50 \mathrm{ohm}$ for line impedance ( $\mathrm{Zo})$. The length and width for the feed line can be calculated using equations (5), (8) and (9).

Feed Length,

$$
\mathrm{Lf}=\frac{L}{2[\text { [reff }]^{1 / 2}}
$$

Feed width,

$$
\mathrm{Zo}=\frac{60}{[\mathrm{\varepsilon reff}]^{1 / 2}} \ln \left[\frac{8 \mathrm{~h}}{\mathrm{Wf}}+\frac{\mathrm{Wf}}{4 \mathrm{~h}}\right]
$$

Where;

$$
\begin{gathered}
\mathrm{h}=\text { substrate thickness } \\
\mathrm{Zo}=\text { line impedance }
\end{gathered}
$$

Table I shows the results calculation of printed rectangular monopole antenna operated at UHF band.

TABLE I: The Parameters of Proposed Antenna
\begin{tabular}{|c|c|c|}
\hline No. & Component & Value \\
\hline 1. & Width of the substrate $(\mathrm{Ws})$ & $100 \mathrm{~mm}$ \\
\hline 2. & Length of the substrate $(\mathrm{Ls})$ & $100 \mathrm{~mm}$ \\
\hline 3. & Width of the patch $(\mathrm{Wp})$ & $72 \mathrm{~mm}$ \\
\hline 4. & Length of the patch $(\mathrm{Lp})$ & $50 \mathrm{~mm}$ \\
\hline 5. & Width of the feed $(\mathrm{Wf})$ & $8 \mathrm{~mm}$ \\
\hline 6. & Length of the feed $(\mathrm{Lf})$ & $40 \mathrm{~mm}$ \\
\hline 7. & Width of the ground $(\mathrm{Wg})$ & $100 \mathrm{~mm}$ \\
\hline 8. & Length of the ground $(\mathrm{Lg})$ & $32.5 \mathrm{~mm}$ \\
\hline 9. & Operating frequency $\left(\mathrm{f}_{\mathrm{o}}\right)$ & $860-960$ \\
\hline
\end{tabular}

\section{Results and Discussion}

The parametric simulation results using the FEKO software of printed rectangular monopole antenna for UHF RFID reader such as reflection coefficient, radiation pattern, and gain are shown. The design of the antenna is shown in Figure3. 


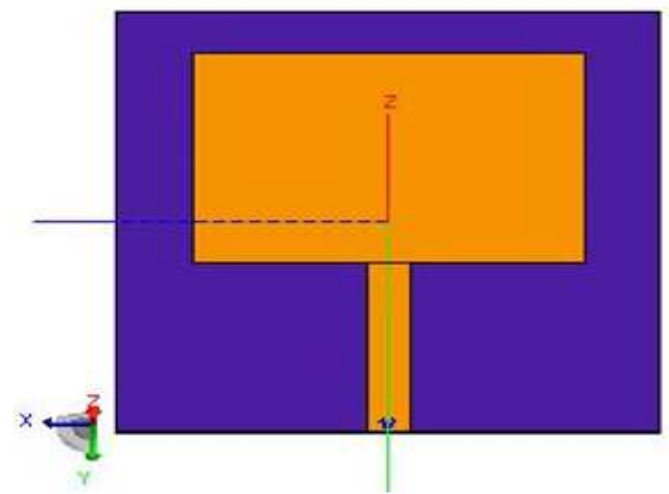

(a)

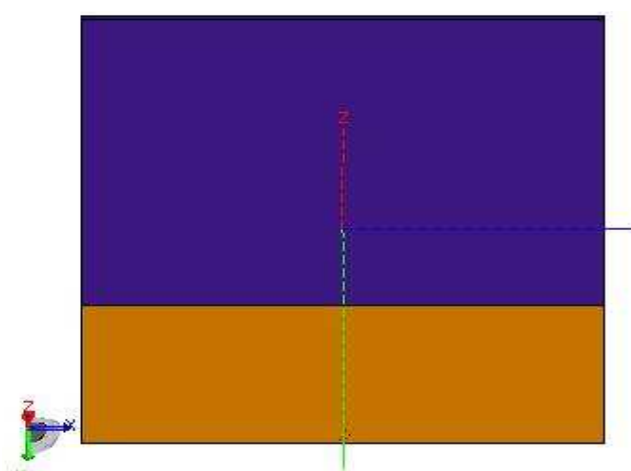

(b)

Figure3.SimulatedAntenna Design (a) Front View (b) Back View

The simulated reflection coefficient of the proposed antenna is shown in Figure4. In order to get a better performance of an antenna, the reflection coefficient should be less than $-10 \mathrm{~dB}$. The simulated reflection coefficient is $-10 \mathrm{~dB}$ on $850-970 \mathrm{MHZ}$ at over the frequency range of RFID Universal UHF band (860$960 \mathrm{MHz}$ ). The obtained bandwidth is $100 \mathrm{MHz}$.

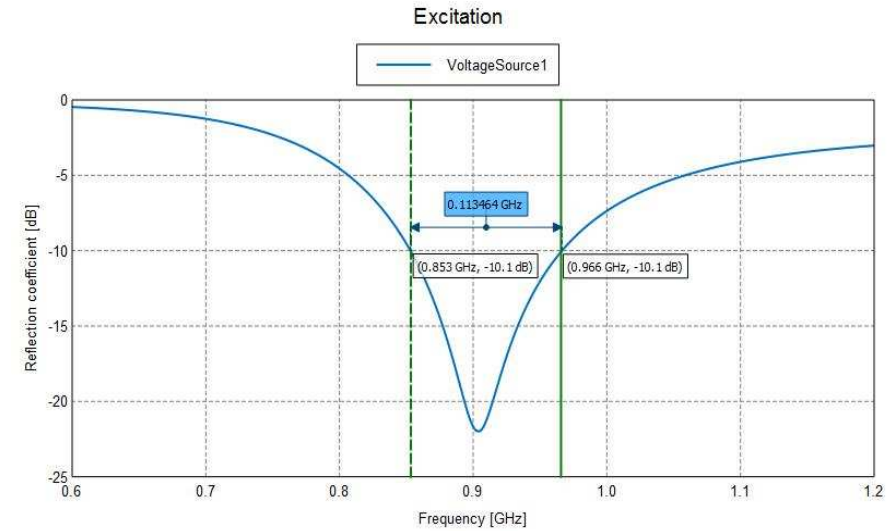

Figure4. The Reflection Coefficient of the Antenna

The simulation result of the proposed antenna gain is shown in Figure5. The designed printed rectangular monopole antenna has a moderate gain of about $1.4 \mathrm{dBi}$ over the desired RFID UHF band of 860-960 $\mathrm{MHz}$.

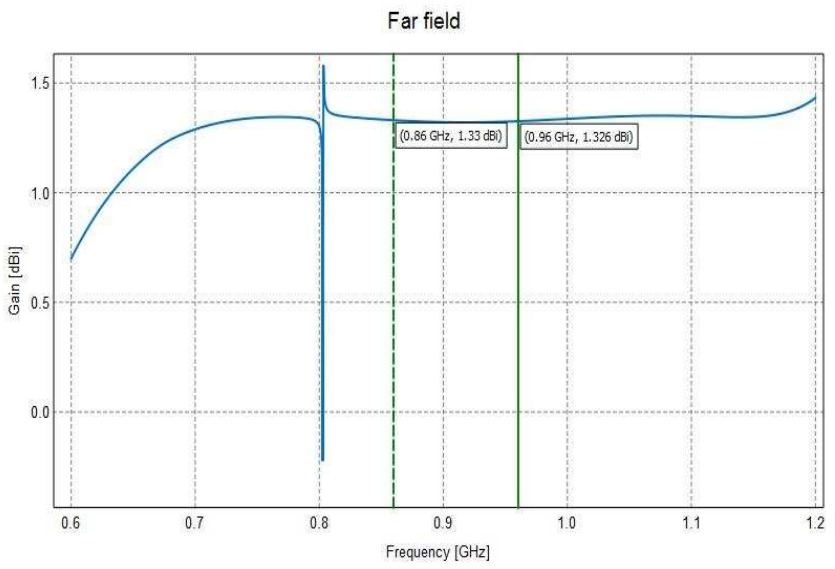

Total Gain [dBi] (Theta $=0$ deg; Phi $=0$ deg $)-3.8 .2018$

Figure5. The Gain of the Antenna

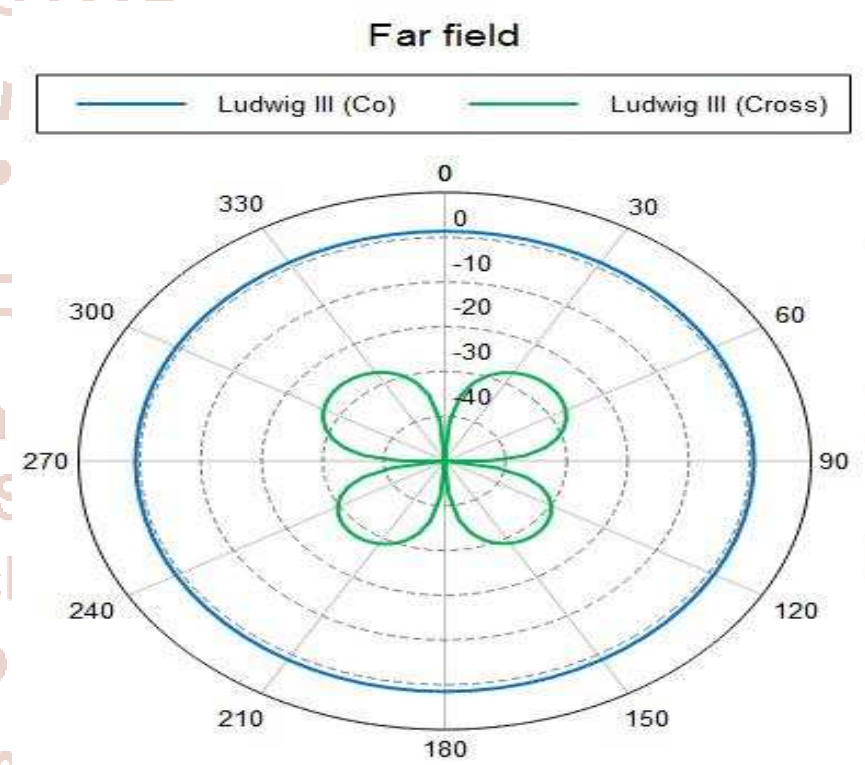

Figure6. The Radiation Pattern of the Antenna

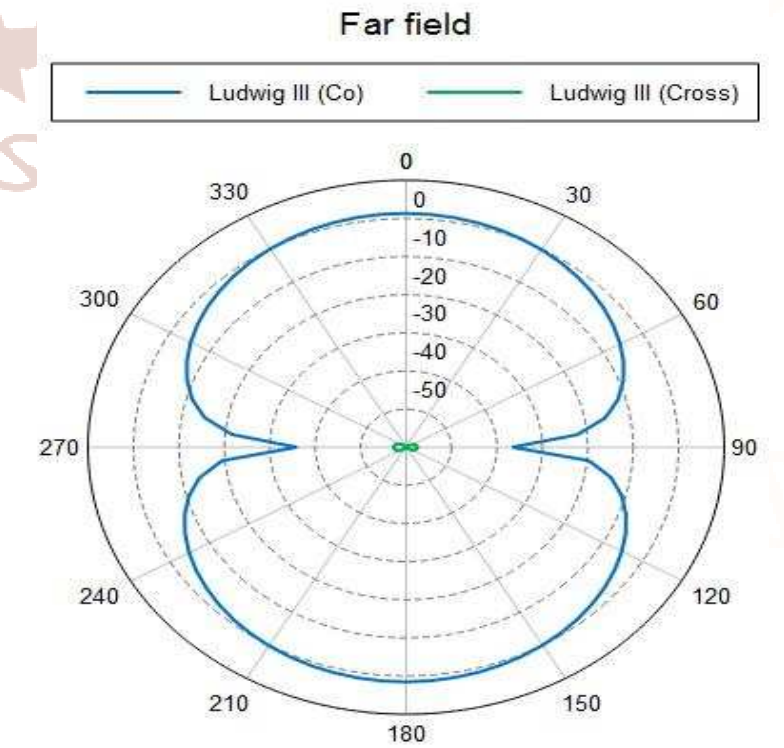

Figure7. The Radiation Pattern of the Antenna 
Another useful measurement describing the performance of antenna is the radiation pattern. An antenna radiation pattern is defined as a mathematical function or graphical representation of the radiation properties of the antenna as a function of space coordinates.Figure6shows the radiation pattern at Phi $=0$ degree and the Figure 7 shows the radiation pattern at $\mathrm{Phi}=90$ degree for the designed antenna at $960 \mathrm{MHz}$.

\section{CONCLUSION}

The printed rectangular monopole antenna becomes a rapidly growing area of research. A printed rectangular monopole antenna was designed and simulated in this paper. The printed rectangular monopole antenna has $-10 \mathrm{~dB}$ at $850-970 \mathrm{MHz}$, a moderate gain of over $1.3 \mathrm{dBi}$ and omnidirectional radiation pattern. Thus this printed rectangular monopole antenna can be used for UHF RFID reader at worldwide frequency band of $860-960 \mathrm{MHz}$.

\section{REFERENCES}

1. R. Want, "An Introduction to RFID Technology," IEEE Pervasive Computing, Vol. 5, Issue 1, Jan. March 2006.
2. Warren L. Stutzman Professor Emeritus Virginia Tech, Gary A. Thiele Professor Emeritus University of Dayton, "Antenna Theory and Design, Third Edition"

3. Melvin M. Weiner (retired) The MITRE Corporation Bedford, Massachusetts, U.S.A, "Monopole Antenna"

4. Syamimi Mohd Norzeli, Ismarani Ismail, Mohd Fazruisyam Mohd Busu Faculty of Electrical Engineering, University Teknologi MARA (UiTM), 40450 Shah Alam, Selangor, Malaysia., "Designing an UHF RFID Antenna "

5. R. A. Oliver, "Broken-loop RFID reader antenna for near field and far field UHFRFID tags, "U.S. Design Patent D570,337S, Jun3, 2008.

6. P. Fuhrer, D. Guinard, and O. Liechti, "RFID: from Concepts to Concrete Implementation," Int. Conf. on Advances in the Internet, Processing, Systems and Interdisciplinary Research (IPSI'06), Marbella, Spain, February 2006. 